\title{
Biomimetic Calcium Phosphate Coating as a Drug Delivery Vehicle for Bone Tissue Engineering: A Mini-Review
}

\author{
Xingnan Lin ${ }^{1,+}$, Jiping Chen ${ }^{1,+}{ }^{(0)}$, Ying Liao ${ }^{2}$, Janak Lal Pathak $\left.{ }^{3}{ }^{(}\right)$, Huang Li $^{1, *}$ and \\ Yuelian Liu $4, *$ \\ 1 Department of Orthodontics, Nanjing Stomatological Hospital, Medical School of Nanjing University, \\ Nanjing 210008, Jiangsu, China; linxingnan@126.com (X.L.); chenjiping@smail.nju.edu.cn (J.C.) \\ 2 Department of Pediatric Dentistry, Nanjing Stomatological Hospital, Medical School of Nanjing University, \\ Nanjing 210008, Jiangsu, China; liaoqiaoling@163.com \\ 3 Guangzhou Key Laboratory of Basic and Applied Research of Oral Regenerative Medicine, \\ Affiliated Stomatology Hospital of Guangzhou Medical University, Guangzhou 510182, China; \\ j.pathak@gzhmu.edu.cn \\ 4 Department of Oral Implantology and Prosthetic Dentistry, Academic Centre of Dentistry \\ Amsterdam (ACTA), VU University and University of Amsterdam, 1081LA Amsterdam, The Netherlands \\ * Correspondence: lihuang76@nju.edu.cn (H.L.); y.liu@acta.nl (Y.L.); \\ Tel.: +86-25-83620173 (H.L.); +31-205188626 (Y.L.) \\ + These authors contribute equally to this paper.
}

Received: 31 October 2020; Accepted: 17 November 2020; Published: 20 November 2020

check for updates

\begin{abstract}
The high incidence of bone defect cases necessitates a rapid development of cost-effective bone tissue engineering approaches. Bone growth factors such as bone morphogenetic protein-2 (BMP-2) play a vital role in bone tissue engineering. The osteoinductive efficacy of BMP-2 and other osteogenic growth factors is highly dependent on their dose and delivery mode. Slow and sustained delivery of a low dose of BMP-2 promotes bone defect healing. However, the burst release of a high dose of BMP-2 not only fails to promote bone healing but also causes adverse local and systemic effects. The biomimetic calcium phosphate (BioCaP) coating technique guarantees a slow, gradual, and local release of BMP-2 to mimic its natural release from the bone matrix under physiological conditions. Therefore, BioCaP coatings have long been regarded as a promising drug carrier for growth factors. In this mini-review, we give a brief introduction to BioCaP coatings regarding their preparation techniques, physicochemical properties, potential as a drug carrier, ability to suppress foreign body reactivity, and their preclinical application in ectopic and orthotopic models. Finally, the current challenges and future prospects of BioCaP coatings are discussed.
\end{abstract}

Keywords: biomimetic; bone morphogenic protein-2; calcium phosphate coating; clinical application; drug delivery; foreign-body reaction; Icariin; preclinical study; parathyroid hormone; vascular endothelial growth factor

\section{Introduction}

High incidence of bone loss resulting from trauma, infection, or disease is evidenced by more than 2 million bone grafts used in orthopedic procedures annually worldwide [1]. While autologous bone serves as the gold standard for bone defect repair, it is associated with morbidity and pain of the donor site [2]. In addition, the insufficient supply of autologous bone has limited its application. Therefore, there is an increasing demand for autologous bone substitutes, which facilitates the rapid development of bone tissue engineering. 
Bone tissue engineering is a sophisticated and dynamic process involving the cooperation of osteoprogenitor cells, various hormones, cytokines, and bone substrates with sufficient mechanical stability to obtain bone growth [3-5]. An osteoconductive surface of bone substrates or implants is vital to permit the differentiated bone cells to move into its pores, channels, and pipes [6]. Various techniques have been utilized to improve the osteoconductivity of bone substrates and implants [7], such as surface roughness and additive calcium phosphate coatings. The common modification strategies to lay down the calcium phosphate coatings on the surfaces of biomaterials include electrostatic or plasma spraying [8,9], coating via sol-gel phase shifting [10], and magnetron sputtering [11,12]. Although the osteoconductivity for implanted biomaterials has been improved by adding a layer of calcium phosphate coating [13-15], the intrinsic osteoinductivity is still lacking [16]. To overcome this problem, bone morphogenic protein-2 (BMP-2)—one of the most potent inducers of osteoblastic differentiation clinically approved by the FDA [17]—is widely used. Most of the techniques used to lay down the calcium phosphate coatings are conducted either under highly unphysiological physical conditions (e.g., magnetron sputtering [12]) or at extremely high temperatures (e.g., plasma spray coating [9]), which preclude the incorporation of biological activity of BMP-2 during the coating process. Thus, BMP-2 is usually directly applied on the scaffold material's surface to which it loosely adsorbs $[18,19]$. However, the in vivo osteoinductive efficiency of BMP-2 is highly dependent on its mode of delivery [20]. It has been proved that this surface-adsorbed depot of BMP-2 is released too rapidly (burst release) to induce a sustained osteogenic response at the site of implantation [21]. Moreover, the burst release of a high dose of BMP-2 in the defect site causes local and systemic adverse effects [22-24]. In order to improve the osteoinductive efficiency of BMP-2, a drug delivery system—namely, biomimetic calcium phosphate (BioCaP) coatings—has been developed [25].

\section{Biomimetic Calcium Phosphate Coatings}

The BioCaP coating technique was first developed in 1990 by Kokubo et al. [26,27] and refined later on by several research groups for preclinical study in bone tissue engineering [24,28-31]. A prominent advantage of the BioCaP coatings is that the biological activity of osteogenic agents/drugs can be preserved during its coprecipitation with the inorganic components under the physiological conditions of temperature $\left(37^{\circ} \mathrm{C}\right)$ and $\mathrm{pH}(7.4)$ [32]. Therefore, the biomimetic coatings incorporated with osteogenic agents can be used to endow the biomaterials with osteoinductivity.

\subsection{Biomimetic Calcium Phosphate Coating Technique}

Two basic procedures are compulsory in the preparation of BioCaP coating (Figure 1): the precipitation of amorphous calcium phosphate (ACP) on the surface of the substrates and the subsequent deposition of the octacalcium phosphate (OCP) coating with targeted drugs on the surface of ACP [33]. First, implant materials are immersed in the 5-time-concentrated simulated body fluid (SBF) for $24 \mathrm{~h}$ under high nucleation conditions (Table 1). Under this circumstance, $\mathrm{Mg}^{2+}$ is utilized to inhibit the growth of crystals and facilitate the development of ACP [34]. Thus, a thin layer $(1-3 \mu \mathrm{m})$ of ACP can uniformly form on the surfaces of the substrates. The ACP layer diffracts natural light and exhibits a multicolored appearance at the fringe, hence being named the "rainbow coating" [35]. Second, an OCP layer with or without protein is obtained by immersing the abovementioned substrates in a supersaturated calcium phosphate solution (Table 1) for $48 \mathrm{~h}$ at $37^{\circ} \mathrm{C}$. As the coprecipitation of proteins with the OCP layer is completely under a physiological condition, the bioactivity of the carried osteogenic agents is well preserved [32]. Except for the abovementioned processes, many modifications of the biomimetic coating techniques have also been explored. The iron concentration of solutions and the reactive conditions (e.g., $\mathrm{pH}$, temperature, and reaction time) [28,36-39] were changed and coatings with similar morphologies were obtained. 


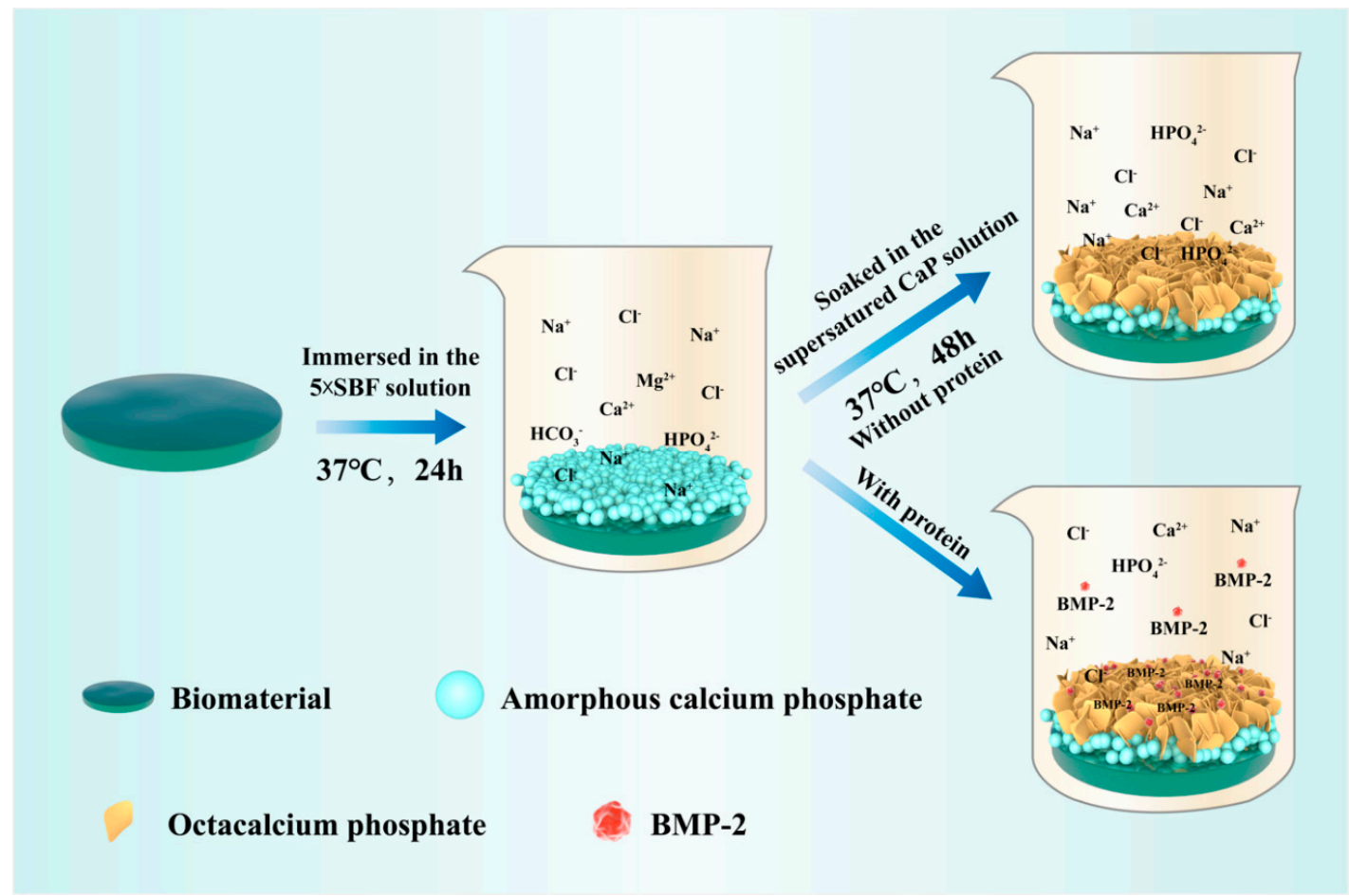

Figure 1. The schematic diagram of the biomimetic coating procedure.

Table 1. Different inorganic compositions and the formation conditions of biomimetic calcium phosphate coatings. SBF-simulated body fluid; ACP-amorphous calcium phosphate; OCP_octacalcium phosphate.

\begin{tabular}{cccccccccccc}
\hline \multirow{2}{*}{ Solutions } & \multicolumn{4}{c}{ Concentrations of Composed Irons $\mathbf{( m M )}$} & \multicolumn{3}{c}{ Reaction Conditions } \\
\cline { 2 - 11 } & $\mathbf{N a}^{+}$ & $\mathbf{K}^{+}$ & $\mathbf{M g}^{2+}$ & $\mathbf{C a}^{\mathbf{2 +}}$ & $\mathbf{C l}^{-}$ & $\mathbf{H P O}_{4}{ }^{2-}$ & $\mathbf{S O}_{4}{ }^{2-}$ & $\mathbf{H C O}_{3}{ }^{-}$ & Time & Temperature & $\mathbf{p H}$ \\
\hline SBF & 142.0 & 5.0 & 1.5 & 2.5 & 147.8 & 1.0 & 0.5 & 4.2 & - & - & 7.4 \\
$\mathrm{ACP}$ & 733.5 & - & 7.5 & 12.5 & 720.0 & 5.0 & - & 21.0 & $24 \mathrm{~h}$ & $37^{\circ} \mathrm{C}$ & 5.8 \\
$\mathrm{OCP}$ & 140.5 & - & - & 4.0 & 144.5 & 2.0 & - & - & $48 \mathrm{~h}$ & $37^{\circ} \mathrm{C}$ & 7.4 \\
\hline
\end{tabular}

\subsection{Features of Biomimetic Calcium Phosphate Coatings}

\subsubsection{Thickness of Coatings}

The coatings were applied on the surfaces of materials with different shapes and the thickness of the coating was evaluated. Liu et al. used the titanium-alloy (Ti6Al4V) plates in 2001 [35] and 2005 [40], and cylindrical dental titanium (Ti) implants in 2007 [20] as substrates of the biomimetic coatings. Analysis of biomimetic coating thickness using magnetic induction probes showed uniform coating with a full thickness of $25.00 \pm 6.4 \mu \mathrm{m}[20,34,35,40]$. The ACP layer is thin and no more than $3 \mu \mathrm{m}$. The thickness of the OCP coating ranges between 30 and $50 \mu \mathrm{m}$ [35], which can be influenced by the presence of incorporated proteins. According to the scanning electron microscopy (SEM) images, the crystals formed in the presence of proteins are smaller, indicating that the growth of the latticework of the OCP layer is inhibited. The crystal size of the OCP layer also decreased as the concentration of incorporated proteins increased.

\subsubsection{Composition and Geometry of Coatings}

The calcium-to-phosphorus $(\mathrm{Ca} / \mathrm{P})$ ratios of the biomimetic coatings are measured by the energy-dispersive $\mathrm{X}$-radiographic analysis. $\mathrm{Wu}$ et al. coated four different types of polymers using this biomimetic method. The Ca/P ratio ranges from 1.53 to 1.64 for the ACP layer. The Ca/P ratio drops in the subsequent deposited OCP layer to the range of 1.37 1.45 [41]. 
SEM images revealed that the BioCaP coatings exhibit a straight, platelike appearance with sharp edges (Figure 2A-C). Previous studies have proved that the morphology and physical characteristic of the coatings are not affected by the 3-dimensional structures of the materials underneath [19,41], but are slightly changed due to the presence of protein [28,35,42], $\mathrm{pH}$ shift, or concentration of the bicarbonate ion $\left(\mathrm{HCO}_{3}{ }^{-}\right)$[36]. As the bovine serum albumin (BSA, model protein) was incorporated, crystals decreased in size and became more compact (Figure 2D) [20,33,34,40,42,43]. This phenomenon was confirmed by another research group $[28,44]$. When prepared in the presence of protein, plates in the coating are severely bent and in contact with the surrounding crystals in a random manner. The extent of bending increases as the concentration of protein enhances. Qu et al. reported that even a $0.1 \mathrm{pH}$ unit shift of the calcium phosphate solution might affect the surface morphology of coating. More porous coatings can be obtained if the primary $\mathrm{pH}$ is lower within the physical range [36]. Besides, the concentration of $\mathrm{HCO}_{3}{ }^{-}$in the calcium phosphate solution is negatively related to the crystallinity of formed coatings [36].
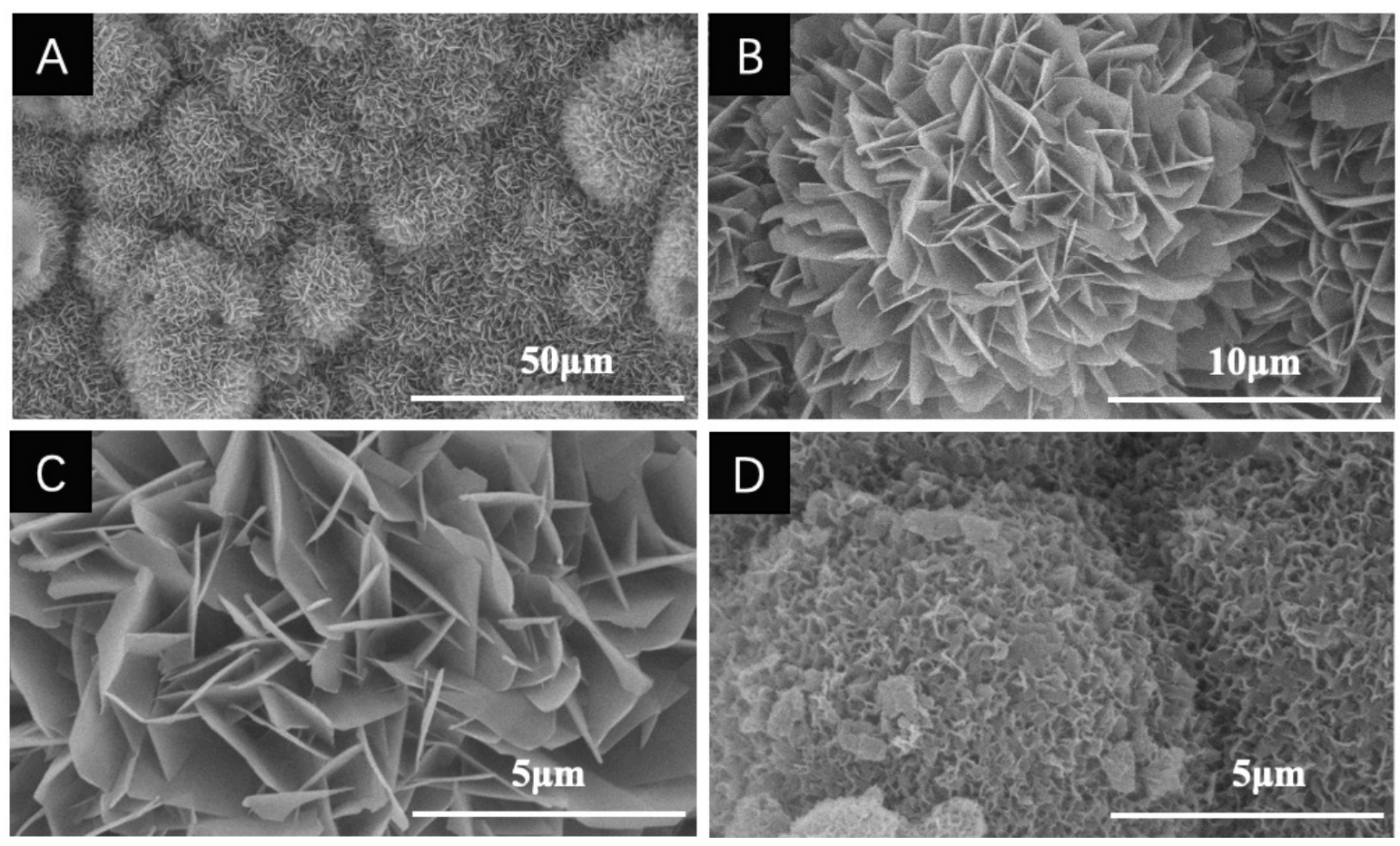

Figure 2. Scanning electron microscopy (SEM) images of the biomimetic calcium phosphate coatings. (A-C) Surface morphology of coatings without protein under different magnifications. (D) Surface morphology of coatings with incorporated proteins (Transforming Growth Factor-beta 3). From the unpublished results from our group.

\subsubsection{The Mechanism of Binding and Release of Drugs Incorporated into Coatings}

In a surface-adsorbed mode, the target molecules, such as BMP-2, are held at the surface of the underlying substrates loosely via an electrostatic interaction [19]. Therefore, the molecules are released rapidly within a biological milieu and diffuse rapidly away from the implantation site, unable to induce an uninterrupted osteogenic stimulus-response [24,45]. In contrast, the target molecules are tightly held by a strong covalent bond in the biomimetic-coating-incorporated mode [41]. Fourier-transform infrared spectroscopy revealed that BSA is incorporated with the latticework of coating via an interaction involving amide-I groups $\left(-\mathrm{CO}=\mathrm{NH}_{2}\right)$ [41]. Besides, Stigter et al. reported a similar interaction between target molecules and BioCaP coatings [46]. Antibiotics demonstrating different chemical structures were incorporated into the carbonated hydroxyapatite (CHA) coatings, which is one of the calcium phosphates, and their release and efficacy against bacteria growth were investigated. They found that antibiotics containing carboxylic groups $(-\mathrm{COOH})$ such as cephalothin, 
carbenicillin, and cefamandole, are able to bind/chelate with calcium, resulting in better incorporation into the CHA coating when compared with antibiotics lacking carboxylic groups [46]. The chelation between calcium and carboxylic group was also confirmed by Ooya et al. [47]. As the number of carboxylic groups grows, the chelation of calcium enhances.

The strong covalent bindings between incorporated drugs and coatings also indicate that the incorporated drugs could only be released when the coatings degrade. As a result, the release of the incorporated component can go along with the degradation of coating, simulating the physical release mode. According to previous studies, the degradation of the calcium phosphate coating is not a spontaneous [35], but a cell-mediated process. To figure out the specific cells involve in coating degradation, bone marrow cells (BMCs) obtained from mice were induced to differentiate respectively into monocytes/macrophages and osteoclasts through the administration of colony stimulating factor-1 (CSF-1) and receptor activator for nuclear factor kappa-B ligand (RANKL) [16,48]. With the help of tritium labeled BSA, the continuous protein release in the presence of monocytes/macrophages or osteoclasts was monitored in vitro during the entire 19-day experimental period [16]. In the presence of osteoclasts, the labeled BSA releases in a sustained mode, suggesting gradual degradation of coatings $[16,48]$. In contrast, absorbed BSA labeled with tritium almost completely releases within the first four days independent of the cocultured cell type. Moreover, the sustained release is interrupted if the calcitonin is added to the culture media, which has been confirmed to inhibit the activity of osteoclasts. In contrast, the above release kinetics are not observed with monocytes/macrophages [16]. Apart from the abovementioned results, SEM images displayed that osteoclasts resorb the apatite crystal structure of coatings, confirming that the sustained release is a result of osteoclastic resorption of the inorganic calcium phosphate layer [16]. The formation and accumulation of multinucleated osteoclasts with absorption pit are also observed on the surface of coated implants in the ectopic rat model [48]. These results confirm that the osteoclasts account for the degradation of coatings. Further, the degradation process of the coatings is biocompatible, displaying nontoxicity, and does not induce inflammation response compared with the synthetic polymers $[49,50]$.

Apart from the gradually cell-mediated degradation of coatings, the homogeneous distribution of the incorporated drugs also accounts for the slow and sustained release mode. The rhodamine-labeled apatite layer of the biomimetic coating and fluorescein isothiocyanate conjugated BSA (FITC-BSA) were colocalized on the surface of the deproteinized bovine bone (DBB) through confocal laser-scanning fluorescence micrographs, confirming that the incorporated drugs distribute homogeneously in the coatings [49]. With the degradation of these biomimetic coatings, the homogeneously incorporated drugs can be released. Liu et al. tested the release modes of proteins with ${ }^{131}$-labeled BMP-2, and the coated implants were inserted under the skin of the rats. During the monitoring period of 5 weeks, BMP-2 incorporated within the biomimetic coatings was liberated in a slow and stable mode, while the absorbed BMP-2 was exhausted after one week [51]. The cell-mediated release process for proteins is similar to the physiological bone remodeling process by virtue of growth factors being released from the bone matrix during its degradation. This appears to be the most efficient way to induce bone formation without overstimulating bone resorption [34]. Therefore, the BioCaP coatings are of great potency for drug delivery in orthopedics.

\subsubsection{In Vivo Degradation of Coatings}

The optimal coatings should be designed to degrade along with the process of bone formation so as to prevent the invasion of bone defect area and leave only the regenerated bone behind [52]. As mentioned above, the degradation of the BioCaP coating is triggered by the formation of osteoclasts $[16,48]$. The resorption rate of the BioCaP coating has been evidenced by several in vivo studies. Liu et al. implanted the Ti6Al4V discs coated with BioCaP coating with or without incorporated BMP-2 in the dorsal region of rats in 2005. The volumes of coatings were calculated with methodologies elaborated by Cruz-Orive and Gunderson et al. on the stained slices [40]. By the end of the 5-week follow-up observation, $77.8 \%$ of the coatings with incorporated BMP-2 were degraded compared with 
the $21.8 \%$ without BMP-2. Meanwhile, the discs modified by BMP-2-incorporated BioCaP coating were almost surrounded by the newly formed bone through the histomorphometric analysis, indicating that the BioCaP coatings do not invade the space for newly formed bone. Hunziker et al. adopted maxilla defects of Goettingen miniature pigs as orthotopic models to test the degradation rate of the BioCaP coatings in 2012 [53]. The Ti implants with or without incorporated BMP-2 were inserted in the maxilla of pigs. They reported the coatings without BMP-2 are degraded by $72 \%$ three weeks of postimplantation compared to almost $100 \%$ in the presence of incorporated BMP-2. The different degradation rates of BioCaP coatings may be due to the difference in the implant environments. The release of BMP-2 and the orthotopic model are more suitable for bone formation, which accelerates the degradation of BioCaP coatings to obtain more $\mathrm{Ca}^{2+}$ and $\mathrm{PO}_{4}{ }^{3-}$ [54]. Besides, Wang et al. applied the BioCaP coatings with different bone graft materials in the critical-sized defects of rat craniums and reported a similar degradation rate of coatings, indicating the degradation of coatings is independent of substrate materials [54].

\subsubsection{The Preservation of Osteoinductive Efficacy of Drugs Incorporated into Coatings}

The advantage of the biomimetic coating strategy is that the osteoinductive agents can be deposited within the apatite crystals layered onto the surface of different bone-implanted materials without impairing their bioactivities, which has been proved by various in vitro and in vivo researches (Table 2). BMCs were seeded on Ti plates coated with BMP-2 via BioCaP coatings and showed higher alkaline phosphatase activity, indicating that BMP-2 incorporation in the coating retained its osteogenic activity [32]. Zhang et al. further confirmed the osteogenic potential of incorporated osteogenic agents in the MC3T3-E1 cell line, as indicated by the higher alkaline phosphatase activity, osteocalcin expression, and mineralization of the extracellular bone matrix [55]. Besides, more newly formed bones can be found around the materials in the presence of incorporated BMP-2 in vivo [48,55-57], suggesting that the BioCaP coatings do not impair the osteogenic activity of BMP-2.

According to the previous study [34], only $3 \%$ to $15 \%$ of the proteins could be incorporated into the coating. The main reason for the low utilization rate of proteins was the relatively large volume of coprecipitation fluid used in these studies. During the coating formation, only a small amount of calcium, phosphate, and protein was incorporated into the inorganic layer. An improvement to enhance the protein's incorporation rate is needed to broaden the clinical application of the biomimetic coating technique. 
Table 2. In vivo biological activities and bone regenerative potential of biomimetic calcium phosphate coatings functionalized with drugs.

\begin{tabular}{|c|c|c|c|c|c|c|c|}
\hline Author and Year & Biomaterial Substrates & Bioactive Agent & Animal Model & Observation Period & Osteogenesis & Angiogenesis & $\begin{array}{c}\text { Foreign Body } \\
\text { Giant Cells }\end{array}$ \\
\hline $\begin{array}{c}\text { Teng F. } \\
\text { Clin Oral Implants } \\
\text { Res } 2020\end{array}$ & DBB & BMP-2 & Mandible of Beagle dogs & 3 months & $\begin{array}{l}\text { Enhanced to a similar extent of } \\
\text { autologous bone graft }\end{array}$ & - & - \\
\hline $\begin{array}{c}\text { Jiang S. } \\
\text { Front. Bioeng. } \\
\text { Biotechnol. } 2020\end{array}$ & BioCaP granules & BMP-2 & Maxilla of Beagle dog & 8 weeks & Enhanced & Enhanced & Reduced \\
\hline $\begin{array}{c}\text { Wei L. } \\
\text { Tissue Eng Part A } \\
2020\end{array}$ & $\beta$-ТСР & BMP-2 & Critical-sized defect of rat cranium & 8 weeks & Enhanced & - & Reduced \\
\hline $\begin{array}{c}\text { Lin X. } \\
\text { Mater Sci Eng C } \\
\text { Mater Biol Appl } \\
2019\end{array}$ & CHA granules & BMP-2 & Dorsal subcutaneous pockets of rats & 5 weeks & Enhanced & - & Reduced \\
\hline $\begin{array}{c}\text { Zhang X. } \\
\text { Front. Pharmacol. } \\
2019\end{array}$ & BioCaP granules & BMP-2+Icariin & Critical-sized defect of rat cranium & 12 weeks & Enhanced & - & - \\
\hline $\begin{array}{c}\text { Wang D. } \\
\text { J Biomed Mater } \\
\text { Res A } 2019\end{array}$ & BioCaP granules & HACC+BMP-2 & Dorsal subcutaneous pockets of rats & 5 weeks & Enhanced & - & Reduced \\
\hline $\begin{array}{c}\text { Liu T. } \\
\text { Sci Rep } 2017\end{array}$ & $\begin{array}{l}\text { BioCaP granules+ } \\
\text { DBB }\end{array}$ & BMP-2 & Humerus and femur defect of sheep & 8 weeks & $\begin{array}{l}\text { Enhanced to a similar extent of } \\
\text { autologous bone graft }\end{array}$ & Newly formed in early stage & Reduced \\
\hline $\begin{array}{c}\text { Yu X. } \\
\text { J Mater Sci: Mater } \\
\text { Med } 2012 \\
\end{array}$ & cpTi foil & PTH & Tibia of mice & 4 weeks & $\begin{array}{l}\text { Dose-dependently improved } \\
\text { osseointegration }\end{array}$ & - & - \\
\hline $\begin{array}{l}\text { Hunziker E.B. } \\
\text { Bone } 2012\end{array}$ & Dental implants & BMP-2 & Maxilla of Goettingen miniature pigs & 3 weeks & Enhanced & - & - \\
\hline $\begin{array}{c}\text { Wu G. } \\
\text { Bone } 2011\end{array}$ & DBB & BMP-2 & Dorsal subcutaneous pockets of rats & 5 weeks & Enhanced & - & Reduced \\
\hline $\begin{array}{l}\text { Hagi T. } \\
\text { Bone } 2010\end{array}$ & Ethisorb ${ }^{\mathrm{TM}}$ discs & BMP-2 & Dorsal subcutaneous pockets of rats & 2 weeks & $\begin{array}{l}\text { Enhanced ossification is independent } \\
\text { of the mechanical environment. }\end{array}$ & - & - \\
\hline $\begin{array}{l}\text { Wu G. } \\
\text { Biomaterials } 2010\end{array}$ & $\begin{array}{c}\text { Collagen; } \\
\text { Ethisorb }^{\mathrm{TM}} ; \\
\text { PLGA; } \\
\text { Polyactive }^{\circledR}\end{array}$ & BMP-2 & Dorsal subcutaneous pockets of rats & 5 weeks & Enhanced & - & Reduced \\
\hline $\begin{array}{l}\text { Wernike E. } \\
\text { Eur Cell Mater } \\
2010\end{array}$ & ВСР & VEGF & Critical-sized defect of rat cranium & 28 days & Enhanced & Enhanced & - \\
\hline $\begin{array}{c}\text { Liu Y. } \\
\text { J Dent Res } 2007\end{array}$ & Ti6Al4V discs & BMP-2 & Dorsal subcutaneous pockets of rats & 5 weeks & Enhanced & - & No effect \\
\hline $\begin{array}{c}\text { Liu Y. } \\
\text { Bone } 2005\end{array}$ & Ti6Al4V discs & BMP-2 & Dorsal subcutaneous pockets of rats & 5 weeks & Enhanced & - & Reduced \\
\hline
\end{tabular}




\section{Biomimetic Calcium Phosphate Coatings as Drug Carriers}

The BioCaP coating is a potential drug carrier for bone defect regeneration. Incorporation with osteoinductive agents can endow the osteoconductive calcium phosphate coating $[14,15]$ with osteoinductivity. The bioactivity of incorporated agents can be preserved. Firstly, if implanted in vivo, the OCP layer can protect the incorporated drugs from diffusing away rapidly, being inactivated by enzymes, or being engulfed by macrophages, unlike the superficially absorbed drugs. Secondly, the drugs incorporated within the coatings can be liberated in a slow and sustained way, along with the osteoclastic degradation of the coating layer $[16,48,51]$. Thus, the retention of drug bioactivity in the defect site is prolonged. More importantly, the formation and degradation of the BioCaP coatings are independent of the surface property of substrates, which has been confirmed by several in vivo studies $[24,28,40,41,49,54,56,58]$. BioCaP coatings with incorporated drugs were formed on the surfaces of inorganic (e.g., Ti discs [24,40], Ti foils [28], BioCaP granules [56], and $\beta$-tricalcium phosphate ( $\beta$-TCP) [58]) or organic (e.g., DBB [49] and natural or synthetic polymers [41]) materials with different shapes and display similar palatelike structures and potent biologic activities (Table 2). This character guarantees that BioCaP coating can be applied for modifications of various implants. Moreover, compared to Ti substrate and tissue culture plate that have a relatively smooth surface, the crystalloid structures of BioCaP coatings are more favorable for cell adhesion, proliferation, and differentiation $[31,43,59]$.

\subsection{Bone Morphogenetic Protein 2}

BMPs, members of the Transforming Growth Factor-Beta (TGF $\beta$ ) superfamily, are the most attractive option for bone tissue engineering as they have been approved to clinically accelerate spinal fusion and bone defect healing [60,61]. Among the different types of BMPs, FDA approves only BMP-2 and BMP-7 for clinical administration, and BMP-2 has demonstrated more potent bone-healing properties compared to BMP-7 [61,62]. Thus, BMP-2 is more widely used in bone regeneration.

Physically, the amount of native BMP-2 is extremely low: only 1 2 $\mu \mathrm{g}$ BMP-2 can be isolated from $1 \mathrm{~kg}$ of cortical bone [23]. In preclinical studies, BMP-2 is usually applied at the supraphysiological level, up to $2.0 \mathrm{mg} / \mathrm{mL}$, and releases rapidly [23]. The high, local concentration of BMP-2 causes complex side effects, such as ectopic bone formation, higher bone resorption, and tumorigenesis [22-24]. Thus, it is necessary to reduce the dosage and manage the mode of delivery of BMP-2. The BioCaP coating is a promising approach for sustained delivery of low dose BMP-2. During the coating procedure, the concentration of BMP-2 in the supersaturated solution of calcium phosphate is usually no more than $10 \mu \mathrm{g} / \mathrm{mL}[20,40,50,56]$. Considering that a fraction of drugs (approximately $3-15 \%$ ) in the supersaturated solution could coprecipitate with the crystalline structures of coatings [34,44], the amount of BMP-2 released in the local environment is comparatively small.

Both the ectopic and orthotopic animal models have been adopted to evaluate the osteoinductive efficacy of BMP-2 incorporated with the biomimetic coating (Table 2). Liu et al. implanted the biomimetically coated Ti discs subcutaneously in the dorsal regions of the rats [24,40]. Newly formed bone lays down directly on the surfaces of coated Ti discs (Figure 3) [40]. The ectopic osteoinductive efficacy of a biomimetic incorporated BMP-2 is 5 70-fold higher than that of an adsorbed depot [24]. Wang and Lin et al. reported the improved osteoinductive efficacy of incorporated BMP-2 in the same ectopic animal model via different implanted biomaterials $[19,50]$. A commonly used orthotopic model is the critical-sized cranial defect of the rat. BMP-2-incorporated $\beta$-TCP and BioCaP were implanted in the critical-sized defect of a rat cranium (diameter of defect: $8 \mathrm{~mm}$ ) [58]. The results demonstrate an enhanced osteoinduction of BMP-2 liberated through the biomimetic coating. Meanwhile, bone defects of different anatomical sites were adopted. A critical bone defect, with a diameter of $8 \mathrm{~mm}$ and a height of $13 \mathrm{~mm}$, was created in the humerus and femur of sheep [63]. Eight weeks postimplantation, the newly formed bone volume in the incorporated BMP-2 group was about 2-fold higher when compared with that in the superficially absorbed BMP-2 group (Figure 4) [63]. Hunziker et al. placed a $6 \mathrm{~mm}$-long cylindrical bolt in the maxillary extraction site of miniature pigs. The highest osteoinductive efficacy 
was obtained when BMP-2 was incorporated in the coatings [53]. Moreover, the bone argumentation via incorporated BMP-2 was also observed in the mandibular defect of Beagle dogs [45]. DBB blocks were implanted in the mandibular bone defect area and Ti implants were inserted into DBB blocks at the same time. According to their results, the osseointegration between DBB blocks and Ti implants and the healing between DBB blocks and defected alveolar bone are both enhanced when BMP-2 is incorporated in the BioCaP coating instead of superficially adsorbed [45]. Apart from the abovementioned administration in dental implantology, BMP-2-incorporated BioCaP grafts have shown a higher osteogenic ability in the alveolar defect site during orthodontic treatment [64]. Alveolar defects of $4.5 \mathrm{~mm}$-diameter and $6 \mathrm{~mm}$-deep were prepared in extraction sites of maxillary first premolars of Beagle dogs. Then, bilateral maxillary second premolars were protracted for 8 weeks to approach the teeth extraction site one week after implantation. Compared with the DBB group, increased newly formed bones, resorption rate of implant materials, and mineralization density of bones with lower root resorption index are found in the BioCaP group functionalized with BMP-2. These results indicate the BMP-2 biomimetically incorporated BioCaP material to be a promising graft material for alveolar defects during orthodontic treatment.

a
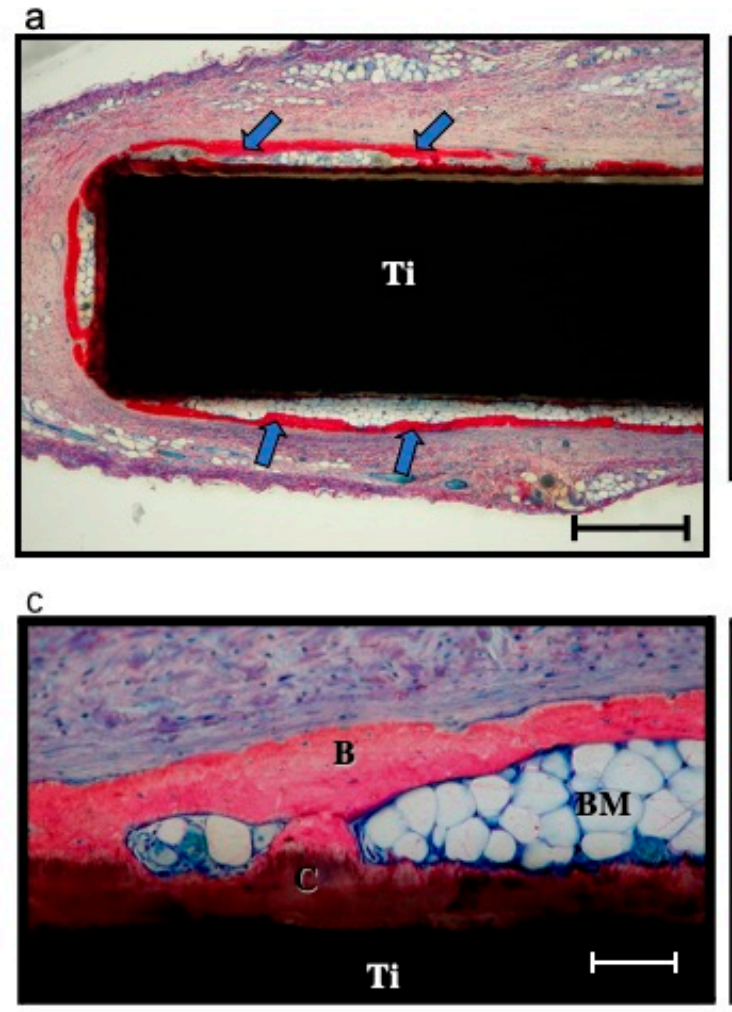

b

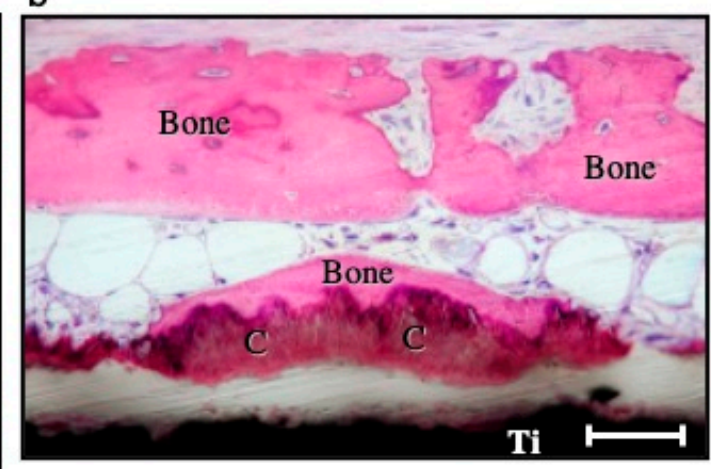

d

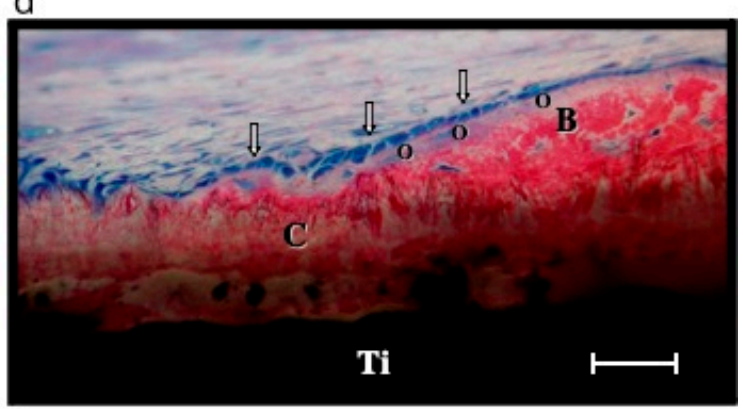

Figure 3. Light micrographs of discs in the incorporated-BMP-2 group, retrieved together with the surrounding tissue 5 weeks after implantation, and stained with McNeil's Tetrachrome, basic Fuchsine, and Toluidine Blue O. (a) Low-magnification view of a disc (Ti) which is almost completely surrounded by bone tissue (arrows). This has been deposited both directly upon the coating and at some distance therefrom within the connective tissue capsule. Scale bar $=0.5 \mathrm{~mm}$. (b) Higher-magnification view of the disc illustrated in (a), showing bone tissue in direct contact with the coating (c) and within the surrounding connective tissue. Scale bar $=20 \mu \mathrm{m}$. (c) Along this stretch of the disc surface, both bone tissue (B) and bone marrow (BM) contact the coating (C) directly. Ti $=$ disc. Bar $=100 \mu \mathrm{m}$. (d) Osteoblasts (arrows) are seen here to be aligned in a characteristic epithelioid fashion upon the surface of osteoid material (o). Ti = disc; $\mathrm{C}=$ coating; $\mathrm{B}=$ bone tissue. Scale bar $=200 \mu \mathrm{m}$. Reprinted with permission [40]; Copyright 2005 Elsevier. 

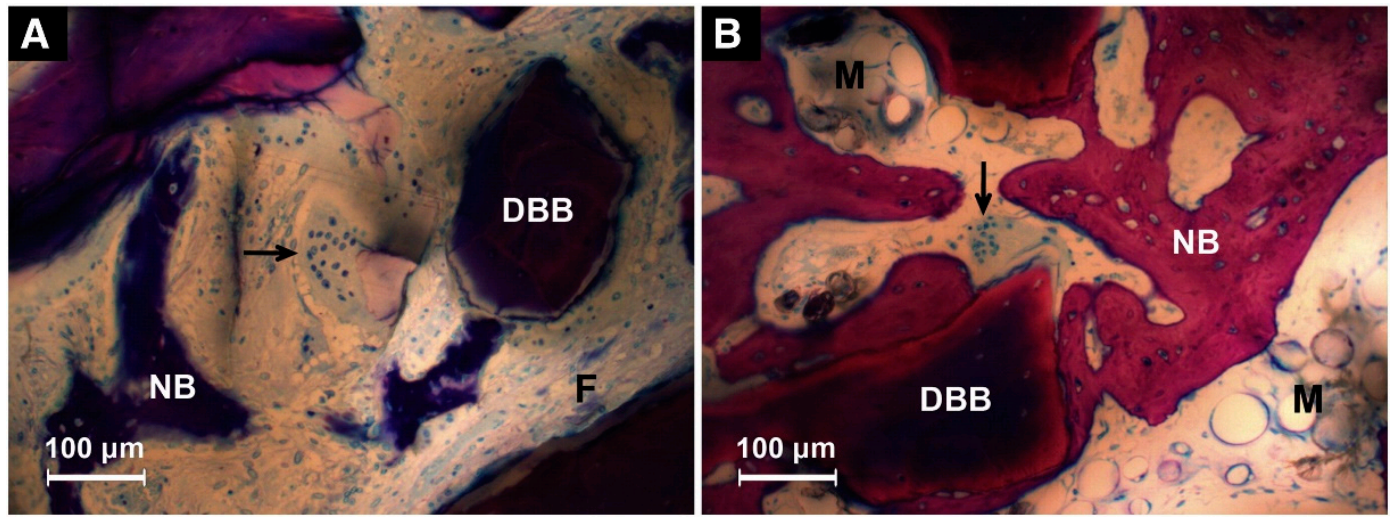

Figure 4. Representative histological sections at 4 weeks of deproteinized bovine bone (DBB) granules that bore an adsorbed depot of BMP-2 (A) and those that bore a coating-incorporated depot of this agent (B). The newly formed bone (NB) was more in contact with the DBB surface and presented more maturely when BMP-2 was incorporated into the coating compared to being adsorbed superficially. At this juncture, a development stage of bone marrow was found around the DBB birthing a coating-incorporated BMP-2 (M). Multinucleated giant cells presented on the surface of DBB (arrow) and the underlying DBB presented a demineralized region (light region). Capsular fibrous tissues (F) were also found around DBB. Scale bar $=100 \mu \mathrm{m}$. Reprinted with permission [63]; Copyright 2013 Elsevier.

Wei et al. evaluated the rat cranial defect healing potential of $\beta$-TCP incorporated with different concentrations of BMP-2 through micro-CT and histological analysis [58]. Different concentrations of incorporated BMP-2 lead to similar levels of bone formation, indicating that the promoted bone formation is not the effect of the dosage of incorporated BMP-2 [58]. Besides, bone formation stimulated by BMP-2 delivered through the biomimetic coating is independent of the mechanical environment. Hagi et al. reported that no matter whether the implant environment is mechanically unstable or stable, the newly formed bone directly lays down on and around implants coated with BMP-2 through an intramembranous way [29].

\subsection{Vascular Endothelial Growth Factor}

The healing procedure of injured bone is disparate from the growth of natural bones. The restoration of injured bone usually starts with the hematoma resulting from the ruined vessels [65]. The relative lower oxygen concentration and $\mathrm{pH}$ in the hematoma area are in favor of bacteria propagation [66], which will damage the integration between natural bone and implanted graft [67]. Moreover, without enough functional vessels, the necrotic soft tissue and bone debris will be detained in the defected area and evoke a mass release of proinflammatory cytokines. Thus, a dense vascular network is also vital for the healing of bone defects. More oxygen, nutrients, and regenerative cells can be supplied into the defect site and the metabolic wastes can be removed in time with the dense vascular network. Angiogenic growth factors, including vascular endothelial growth factor (VEGF), have attracted more attention recently [68]. However, a narrow range of therapeutic windows limits the promotion of VEGF. High concentrations of VEGF are shown to result in unfavorable effects, such as increased permeability and leakage of vessels. Moreover, high VEGF concentrations are prone to create malformed and nonfunctional blood vessels $[68,69]$. Furthermore, the short half-life of VEGF limits its effectiveness as a large proportion of VEGF degrades rapidly before coming into effect if being released into the biological milieu [68]. Therefore, it is necessary to reduce the local concentration of VEGF and prolong its activity. The BioCaP coating was used to improve the retention of VEGF on the biphasic calcium phosphate (BCP) ceramics [69]. During the monitoring period (19 days) in vitro, only half of the VEGF released slowly. When the VEGF-incorporated BCP ceramics are implanted in the cranial defects of mice, dense vessels can be visualized with intravital microscopy. VEGF incorporation into the 
coatings instead of through superficial adsorption gives a more regular morphology of the blood vessels and functional vessels. Sustainedly resealed VEGF induces osteogenesis more prominently $[70,71]$. Wernike et al. reported that VEGF enhances the neo-osteogenesis within the pores of the materials in the cranial defect of mice when it is incorporated into the coating and released slowly as the coatings gradually degrade [69].

\subsection{Antibacterial Drugs}

According to the literature, approximately $1-5 \%$ of implanted biomaterials of orthopedic surgery failed because of bacteria-associated infections [72,73]. In order to inhibit the infection, antibiotics were administrated systematically. However, the systematic administration dosage is subject to the underlying organ toxicity [66] and the local penetration of antibiotics is usually too low to inhibit the proliferation of bacteria [33]. Thus, a local delivery system that can locally load a sustained higher concentration of antibiotics on the target areas without organ toxicity is needed. The BioCaP coatings have been used to sustainedly liberate antibacterial drugs, such as antibiotics and $\mathrm{Ag}^{+}$. The bioactivity of the antibacterial drugs was well maintained $[33,43,74,75]$. Liu et al. deposited a high concentration of metronidazole (MNZ) within the BioCaP coatings, approximately twice the maximum blood concentration [76], without affecting cell proliferation [43]. The slow release of the high-concentration MNZ not only induced significant growth inhibition of bacteria, but also enhanced the osteogenic differentiation of cells compared with coatings without MNZ [43]. Besides, hydroxypropyltrimethyl ammonium chloride chitosan (HACC, an antibacterial agent) was incorporated with the crystal latticework of BioCaP coatings in the presence of BMP-2 [77]. When implanted in the ectopic rat model, the local release of HACC inhibits the growth of bacteria and a maximum bone formation is observed under the dual release of HACC and BMP-2. The suppressed inflammatory response may account for the above results, as the reduced inflammation is beneficial for bone formation.

\subsection{Icariin}

Although BMP-2 displays a superior ability to induce bone formation, its high price makes bone regeneration costly. Thus, it is essential to explore an alternative drug for BMP-2. Recently, a traditional Chinese medicine Icariin, the main therapeutic component of a traditional medicine Herba Epimedii, is reported to be cost-efficient, osteoinductive, and nontoxic [78-81]. This makes it an attractive alternative for BMP-2 in bone tissue engineering; however, the half-life of Icariin is too short to maintain a therapeutic concentration in bone defects. Hence, Icariin released in a sustained manner in a bone defect area is necessary. Our previous study suggested that BioCaP coating is an attractive slow-release delivery vehicle for proteins $[24,25,32,48,63]$. Zhang et al. evaluated the osteogenic potential of Icariin via BioCaP coatings [55]. BioCaP granules coated with OCP coatings in the absence or presence of Icariin or/and BMP-2 gave sustained release of Icariin for at least 12 weeks and enhanced bone mineral density in the rat cranial bone defect. OCP coating with both Icariin and BMP-2 induced significantly more newly formed bones compared to coating with Icariin or BMP-2 alone, indicating a synergistic effect of the two components (Figure 5) [55]. This may be due to the fact that the incorporated Icariin stimulates the upregulation of BMP-2 gene expressions [82]. 
A

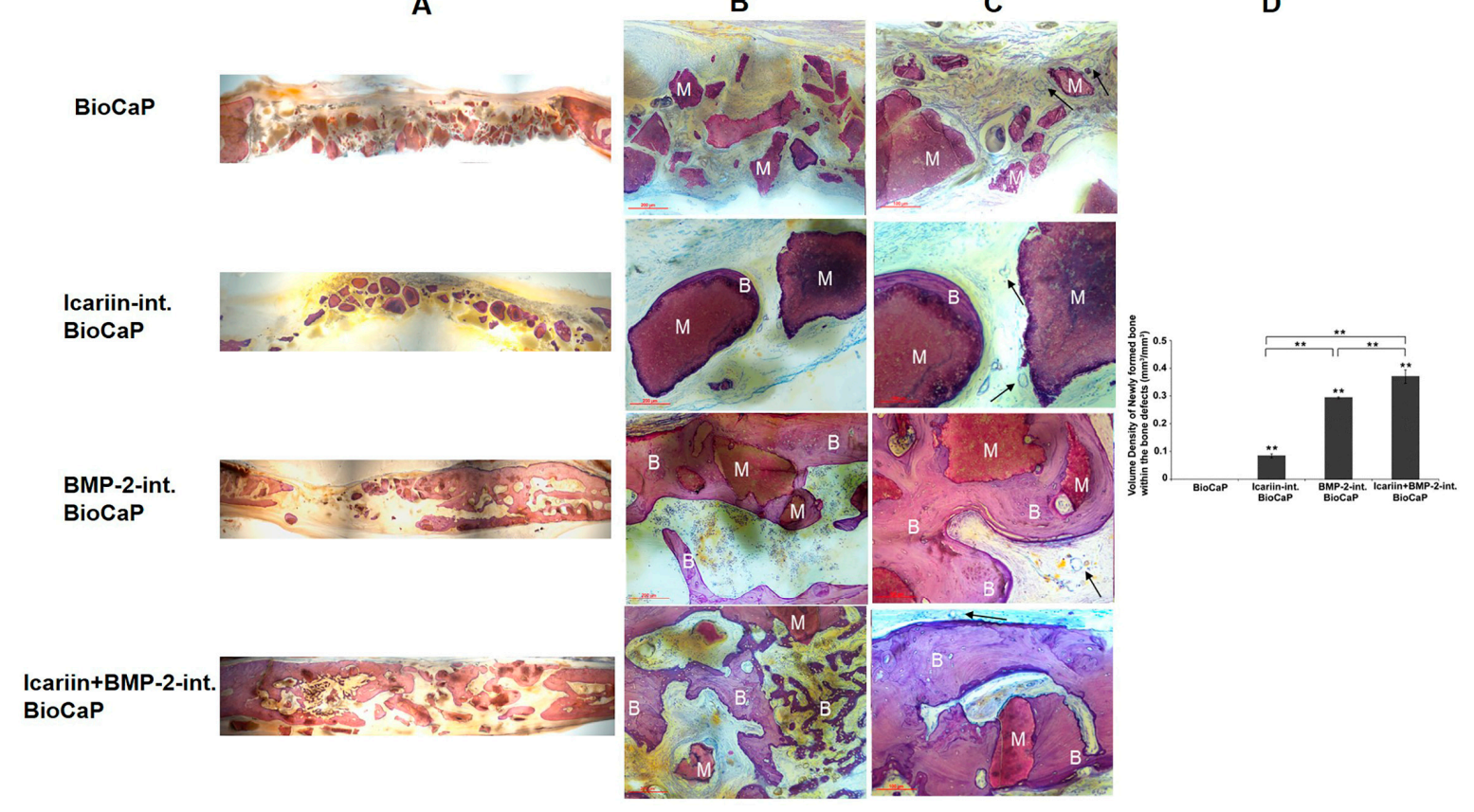

Figure 5. Representative histological micrographs of bone defect of each group at 12 weeks after implantation. The BioCaP granules materials $(\mathrm{M})$ were surround by newly formed bone (B) in Icariin-int. BioCaP, BMP-2-int. BioCaP, and Icariin + BMP-2-int. BioCaP Groups. The slices were surface-stained with McNeal's Tetrachrome, basic Fuchsine, and Toluidine Blue. (A) The panoramic images of the defects of four experiment groups. (B) Scale bar $=200 \mu \mathrm{m}$. (C) Scale bar $=100 \mu \mathrm{m}$. The vascular (black arrows) was observed in all the groups. (D) The volume of newly formed bone within the bone defect after 12 weeks postoperation for each group which is analyzed by histology. Mean values ( $n=6$ specimens per group) are represented together with the standard deviation. ${ }^{* *}$ indicates $p<0.01$. Reprinted from [55].

\subsection{Parathyroid Hormone}

The parathyroid hormone (PTH) is associated with the regulation of $\mathrm{Ca}^{2+}$ and $\mathrm{PO}_{4}{ }^{3-}$ in the human body, especially in bones [83], and it can directly activate osteoblasts by upregulating RANKL expression. The PTH has been proven to be effective in stimulating bone formation in various animal models and humans [84-86]. However, systematic administration of PTH is inconvenient as it is required to be injected intermittently—daily injection, for example—to maintain its therapeutic effects $[86,87]$. Moreover, overdosage of PTH may in turn activate the osteoclastic activity [88]. Hence, it is urgent to explore a local delivery system to avoid the inconvenient administration mode of PTH and maintain the osteogenic property at the same time. Yu et al. $[28,87]$ successfully incorporated the PTH into BioCaP coatings. PTH released from the coating retains superior bioactivity as increased proliferation of MC3T3-E1 cells is observed [87]. Yu et al. made a $0.5 \mathrm{~mm}$ hole on the tibia of mice. Ti foil coated with different concentrations of PTH was inserted into the hole. The most newly formed bone surrounding the implant is found in the group incorporated with PTH $(100 \mu \mathrm{g} / \mathrm{mL})$ according to micro-CT [28].

\section{Delivering Multicomponent Molecules in Sequence}

The whole process of bone defect healing can be divided into different stages, and bioactive molecules with various functions are indispensable $[65,89]$. Considering that the healing procedure is associated with healing time, the corresponding stimulus should be delivered sequentially. Moreover, if exposed to the environment simultaneously, the bioactivity of different molecules may be antagonistic to each other, such as the osteogenic and osteoclastic stimulus. The BioCaP coatings have been utilized to release multiple components in sequence. On the one hand, the surface 
and crystal structure of the coatings can deliver two different components. Wang et al. incorporated the BMP-2 within the crystal structure of coatings and then superficially absorbed antibacterial agent HACC on the surfaces of coatings [77]. The HACC liberates firstly due to the burst release effects. The incorporated BMP-2 releases secondarily along with the slow degradation of coatings. A maximum bone formation is observed under the dual release of HACC and BMP-2 in the ectopic rat model [77]. The mass release of HACC in the first step may reduce the inflammatory response, beneficial for bone formation. On the other hand, the BioCaP coating can serve as a biodegradable barrier for different bioactive molecules. Alhamdi et al. successfully utilized the biomimetic coatings for the sequential release of interferon-gamma (IFN- $\gamma$ ) and simvastatin to control the phenotype transition of macrophages [31]. Macrophages can be divided into proinflammatory phenotype and proreparative phenotype, referred to as M1 and M2, respectively. M1 starts the osteogenesis and M2 regulates the deposition and remodeling [90-92]. The appropriate transition between M1 and M2 can lead to a better bone defect repairment [31] as the stalled transition will hinder the bone healing process [93]. Simvastatin, stimulating the transition to M2 macrophages, was adsorbed directly on the top surface of substrate disks. Then, a BioCaP coating was deposited on the surface of simvastatin as a barrier to impede the liberation of simvastatin. Afterward, the M1 promoting agent IFN- $\gamma$ was adsorbed on the surface of coatings. The simvastatin-coating-IFN- $\gamma$ complex was cultured with macrophages. The sequential increased expression of M1 markers and M2 markers confirms the ability of coatings as a barrier for the sequential administration of two molecules. Except for the abovementioned drugs, various molecules such as fibroblast growth factor 2 and antimycin A have been sequentially liberated with the barrier effect of the BioCaP coatings $[30,94]$.

\section{Suppress the Foreign-Body Reactivity}

The inflammatory environment induces the fusion of monocytes/macrophages into multinucleated giant cells, also known as foreign body giant cells (FBGCs). The accumulation of FBGCs is one of the most important factors that affect bone repair. FBGCs impair the bone regeneration not only through the resorption of the natural bone, but also via proinflammatory-cytokines-mediated inhibition of bone neoformation [64]. DBB is a widely utilized material for the repair of large bone defects. However, the intrinsic poor biocompatibility of DBB limits its application in bone regeneration [64], as poor biocompatible materials will evoke inflammations mediated by foreign body reaction in the defect area $[95,96]$. According to the previous in vivo study, macrophages accumulate around DBB only two days after implantation [49]. After 2 to 10 days, FBGCs fuse from macrophages and result in treatment failure [49]. In our previous studies, subcutaneous implantation of DBB coated with BMP-2 in rats reduced the number of FBGCs [40,49]. Lin et al. further confirmed this finding [19]. The amount of FBGCs around coralline hydroxyapatite coated with the biomimetic coating was decreased significantly, whether in the presence of BMP-2 or not. Two different mechanisms can explain the improvement of biocompatibility. On the one hand, the continuously released BMP-2 and the crystal apatite of the OCP layer upregulate osteopontin expression, which competitively binds the surface receptors of CD44 on macrophages and suppresses multinucleation of macrophages [19,49,97]. As a result, the fusion of FBGCs is hindered and inflammation is alleviated $[19,49,98]$. On the other hand, the bone formation accelerated by calcium phosphate coatings without or with BMP-2 bears a negative correlation with the inflammatory responses $[19,49]$.

\section{Conclusions}

The merits of the biomimetic coating technique have broadened the potential of BioCaP coatings to serve as a suitable carrier for osteogenic drugs. BioCaP coatings render osteoinductive and osteoconductive properties of inert biomaterials. Meanwhile, the bioactivity of osteogenic agents and growth factors can be preserved during their coprecipitation with apatite crystals. The retention period of osteogenic stimulus is considerably prolonged with the slow degradation of the BioCaP coatings. The concentration of drugs retained in the local environment is relatively low, which can alleviate or 
even eliminate the side effects caused by conventional surface-adsorption administration. In addition, the new bone formation induced by BMP- 2 incorporated into calcium phosphate coatings via biomimetic way is independent of the mechanical environment. They are of great potential value as a drug-carrier system in dental, orthopedic, and maxillofacial surgery.

Author Contributions: Conceptualization and supervision, H.L. and Y.L. (Yuelian Liu); writing-original draft preparation, X.L. and J.C.; writing - review and editing, Y.L. (Ying Liao) and J.L.P. All authors have read and agreed to the published version of the manuscript.

Funding: This work was funded by the National Natural Science Foundation of China [grant number: 81670960], Fundamental Research Funds for the Central Universities [grant number 0214-14380489]; the Jiangsu Natural Science Funds [grant number SBK2020041847] and the Nanjing Scientific Innovation Project for Overseas Researchers [grant number 2019-C-173].

Conflicts of Interest: The authors declare no conflict of interest.

\section{References}

1. Huang, Q.; Xu, S.; Ouyang, Z.; Yang, Y.; Liu, Y. Multi-scale nacre-inspired lamella-structured Ti-Ta composites with high strength and low modulus for load-bearing orthopedic and dental applications. Mater. Sci. Eng. C 2021, 118, 111458. [CrossRef]

2. Tuchman, A.; Brodke, D.S.; Youssef, J.A.; Meisel, H.-J; Dettori, J.R.; Park, J.-B.; Yoon, S.T.; Wang, J.C. Iliac crest bone graft versus local autograft or allograft for lumbar spinal fusion: A systematic review. Glob. Spine J. 2016, 6, 592-606. [CrossRef]

3. Erten, E.; Arslan, Y.E. The great harmony in translational medicine: Biomaterials and stem cells. Adv. Exp. Med. Biol. 2018, 1119, 21-39. [CrossRef] [PubMed]

4. Bose, S.; Roy, M.; Bandyopadhyay, A. Recent advances in bone tissue engineering scaffolds. Trends Biotechnol. 2012, 30, 546-554. [CrossRef] [PubMed]

5. Alexandrova, R.; Abudalleh, A.; Andonova-lilova, B.; Zhivkova, T.; Mitrenga, P.; Dyakova, L.; Alexandrov, O.; Dinev, D.; Spasova, S.; Sigurjonsson, O. Bone tissue engineering. In Proceedings of the IX Workshop on Biological Activity of Metals, Synthetic Compounds and Natural Products, Sofia, Bulgaria, 26-28 November 2014.

6. Albrektsson, T.; Johansson, C. Osteoinduction, osteoconduction and osseointegration. Eur. Spine J. 2001, 10 (Suppl. 2), S96-S101. [CrossRef] [PubMed]

7. El-Banna, A.; Bissa, M.W.; Khurshid, Z.; Zohaib, S.; Asiri, F.Y.I.; Zafar, M.S. 4-Surface modification techniques of dental implants. In Dental Implants; Woodhead Publishing: Duxford, UK, 2020; pp. 49-68. ISBN 978-0-12-819586-41.

8. Siebers, M.C.; Walboomers, X.F.; Leeuwenburgh, S.C.; Wolke, J.G.; Jansen, J.A. Electrostatic spray deposition (ESD) of calcium phosphate coatings, an in vitro study with osteoblast-like cells. Biomaterials 2004, 25, 2019-2027. [CrossRef] [PubMed]

9. Graziani, G.; Bianchi, M.; Sassoni, E.; Russo, A.; Marcacci, M. Ion-substituted calcium phosphate coatings deposited by plasma-assisted techniques: A review. Mater. Sci. Eng. C 2017, 74, 219-229. [CrossRef] [PubMed]

10. Asri, R.I.M.; Harun, W.S.W.; Hassan, M.A.; Ghani, S.A.C.; Buyong, Z. A review of hydroxyapatite-based coating techniques: Sol-gel and electrochemical depositions on biocompatible metals. J. Mech. Behav. Biomed. Mater. 2016, 57, 95-108. [CrossRef]

11. Surmeneva, M.A.; Chaikina, M.V.; Zaikovskiy, V.I.; Pichugin, V.F.; Buck, V.; Prymak, O.; Epple, M.; Surmenev, R.A. The structure of an RF-magnetron sputter-deposited silicate-containing hydroxyapatite-based coating investigated by high-resolution techniques. Surf. Coat. Technol. 2013, 218, 39-46. [CrossRef]

12. Qadir, M.; Li, Y.; Wen, C. Ion-substituted calcium phosphate coatings by physical vapor deposition magnetron sputtering for biomedical applications: A review. Acta Biomater. 2019, 89, 14-32. [CrossRef]

13. Kazimierczak, P.; Przekora, A. Osteoconductive and osteoinductive surface modifications of biomaterials for bone regeneration: A concise review. Coatings 2020, 10, 971. [CrossRef]

14. Oyane, A.; Nakamura, M.; Sakamaki, I.; Shimizu, Y.; Miyata, S.; Miyaji, H. Laser-assisted wet coating of calcium phosphate for surface-functionalization of PEEK. PLoS ONE 2018, 13, e0206524. [CrossRef] [PubMed] 
15. Najeeb, S.; Khurshid, Z.; Matinlinna, J.P.; Siddiqui, F.; Nassani, M.Z.; Baroudi, K. Nanomodified peek dental implants: Bioactive composites and surface modification-A review. Int. J. Dent. 2015, 2015, 381759. [CrossRef] [PubMed]

16. Wernike, E.; Hofstetter, W.; Liu, Y.; Wu, G.; Sebald, H.J.; Wismeijer, D.; Hunziker, E.B.; Siebenrock, K.A.; Klenke, F.M. Long-term cell-mediated protein release from calcium phosphate ceramics. J. Biomed. Mater. Res. A 2010, 92, 463-474. [CrossRef]

17. Biase, P.D.; Capanna, R. Clinical applications of BMPs. Injury 2005, 36, S43-S46. [CrossRef]

18. Nandi, S.K.; Kundu, B.; Mukherjee, J.; Mahato, A.; Datta, S.; Balla, V.K. Converted marine coral hydroxyapatite implants with growth factors: In vivo bone regeneration. Mater. Sci. Eng. C 2015, 49, 816-823. [CrossRef]

19. Lin, X.; Hunziker, E.B.; Liu, T.; Hu, Q.; Liu, Y. Enhanced biocompatibility and improved osteogenesis of coralline hydroxyapatite modified by bone morphogenetic protein 2 incorporated into a biomimetic coating. Mater. Sci. Eng. C 2019, 96, 329-336. [CrossRef]

20. Liu, Y.; Enggist, L.; Kuffer, A.F.; Buser, D.; Hunziker, E.B. The influence of BMP-2 and its mode of delivery on the osteoconductivity of implant surfaces during the early phase of osseointegration. Biomaterials 2007, 28, 2677-2686. [CrossRef]

21. Haidar, Z.S.; Hamdy, R.C.; Tabrizian, M. Delivery of recombinant bone morphogenetic proteins for bone regeneration and repair. Part A: Current challenges in BMP delivery. Biotechnol. Lett. 2009, 31, 1817-1824. [CrossRef]

22. Halloran, D.; Durbano, H.W.; Nohe, A. Bone morphogenetic protein-2 in development and bone homeostasis. J. Dev. Biol. 2020, 8, 19. [CrossRef]

23. Park, S.-Y.; Kim, K.-H.; Kim, S.; Lee, Y.-M.; Seol, Y.-J. BMP-2 Gene delivery-based bone regeneration in dentistry. Pharmaceutics 2019, 11, 393. [CrossRef] [PubMed]

24. Liu, Y.; Huse, R.O.; de Groot, K.; Buser, D.; Hunziker, E.B. Delivery mode and efficacy of BMP-2 in association with implants. J. Dent. Res. 2007, 86, 84-89. [CrossRef] [PubMed]

25. Liu, Y.; de Groot, K.; Hunziker, E.B. Osteoinductive implants: The mise-en-scène for drug-bearing biomimetic coatings. Ann. Biomed. Eng. 2004, 32, 398-406. [CrossRef] [PubMed]

26. Kokubo, T.; Kushitani, H.; Sakka, S.; Kitsugi, T.; Yamamuro, T. Solutions able to reproduce in vivo surface-structure changes in bioactive glass-ceramic A-W. J. Biomed. Mater. Res. 1990, 24, 721-734. [CrossRef] [PubMed]

27. Kokubo, T.; Ito, S.; Huang, Z.T.; Hayashi, T.; Sakka, S.; Kitsugi, T.; Yamamuro, T. Ca, P-rich layer formed on high-strength bioactive glass-ceramic A-W. J. Biomed. Mater. Res. 1990, 24, 331-343. [CrossRef] [PubMed]

28. Yu, X.; Wang, L.; Jiang, X.; Rowe, D.; Wei, M. Biomimetic CaP coating incorporated with parathyroid hormone improves the osseointegration of titanium implant. J. Mater. Sci. Mater. Med. 2012, 23, 2177-2186. [CrossRef]

29. Hagi, T.T.; Wu, G.; Liu, Y.; Hunziker, E.B. Cell-mediated BMP-2 liberation promotes bone formation in a mechanically unstable implant environment. Bone 2010, 46, 1322-1327. [CrossRef]

30. Jacobs, E.E.; Gronowicz, G.; Hurley, M.M.; Kuhn, L.T. Biomimetic calcium phosphate/polyelectrolyte multilayer coatings for sequential delivery of multiple biological factors. J. Biomed. Mater. Res. A 2017, 105, 1500-1509. [CrossRef]

31. Alhamdi, J.R.; Peng, T.; Al-Naggar, I.M.; Hawley, K.L.; Spiller, K.L.; Kuhn, L.T. Controlled M1-to-M2 transition of aged macrophages by calcium phosphate coatings. Biomaterials 2019, 196, 90-99. [CrossRef]

32. Liu, Y.; Hunziker, E.B.; Layrolle, P.; De Bruijn, J.D.; De Groot, K. Bone morphogenetic protein 2 incorporated into biomimetic coatings retains its biological activity. Tissue Eng. 2004, 10, 101-108. [CrossRef]

33. Stigter, M.; de Groot, K.; Layrolle, P. Incorporation of tobramycin into biomimetic hydroxyapatite coating on titanium. Biomaterials 2002, 23, 4143-4153. [CrossRef]

34. Lin, X.; de Groot, K.; Wang, D.; Hu, Q.; Wismeijer, D.; Liu, Y. A review paper on biomimetic calcium phosphate coatings. Open Biomed. Eng. J. 2015, 9, 56-64. [CrossRef] [PubMed]

35. Liu, Y.; Layrolle, P.; de Bruijn, J.; van Blitterswijk, C.; de Groot, K. Biomimetic coprecipitation of calcium phosphate and bovine serum albumin on titanium alloy. J. Biomed. Mater. Res. 2001, 57, 327-335. [CrossRef]

36. Qu, H.; Wei, M. The effect of temperature and initial $\mathrm{pH}$ on biomimetic apatite coating. J. Biomed. Mater. Res. B Appl. Biomater. 2008, 87, 204-212. [CrossRef] [PubMed] 
37. Zhou, R.; Xu, W.; Chen, F.; Qi, C.; Lu, B.-Q.; Zhang, H.; Wu, J.; Qian, Q.-R.; Zhu, Y.-J. Amorphous calcium phosphate nanospheres/polylactide composite coated tantalum scaffold: Facile preparation, fast biomineralization and subchondral bone defect repair application. Colloids Surf. B 2014, 123, $236-245$. [CrossRef]

38. Wen, H.B.; Moradian-Oldak, J. Modification of calcium-phosphate coatings on titanium by recombinant amelogenin. J. Biomed. Mater. Res. 2003, 64A, 483-490. [CrossRef]

39. Budnicka, M.; Szymaniak, M.; Kołbuk, D.; Ruśkowski, P.; Gadomska-Gajadhur, A. Biomineralization of poly-l-lactide spongy bone scaffolds obtained by freeze-extraction method. J. Biomed. Mater. Res. Part B Appl. Biomater. 2020, 108, 868-879. [CrossRef]

40. Liu, Y.; de Groot, K.; Hunziker, E.B. BMP-2 liberated from biomimetic implant coatings induces and sustains direct ossification in an ectopic rat model. Bone 2005, 36, 745-757. [CrossRef]

41. Wu, G.; Liu, Y.; Iizuka, T.; Hunziker, E.B. Biomimetic coating of organic polymers with a protein-functionalized layer of calcium phosphate: The surface properties of the carrier influence neither the coating characteristics nor the incorporation mechanism or release kinetics of the protein. Tissue Eng. Part C Methods 2010, 16, 1255-1265. [CrossRef]

42. Hagi, T.T.; Enggist, L.; Michel, D.; Ferguson, S.J.; Liu, Y.; Hunziker, E.B. Mechanical insertion properties of calcium-phosphate implant coatings. Clin. Oral Implants Res. 2010, 21, 1214-1222. [CrossRef]

43. Liu, Y.; Zhang, X.; Liu, Y.; Jin, X.; Fan, C.; Ye, H.; Ou, M.; Lv, L.; Wu, G.; Zhou, Y. Bi-functionalization of a calcium phosphate-coated titanium surface with slow-release simvastatin and metronidazole to provide antibacterial activities and pro-osteodifferentiation capabilities. PLoS ONE 2014, 9, e97741. [CrossRef]

44. Yu, X.; Qu, H.; Knecht, D.A.; Wei, M. Incorporation of bovine serum albumin into biomimetic coatings on titanium with high loading efficacy and its release behavior. J. Mater. Sci. Mater. Med. 2009, 20, $287-294$. [CrossRef]

45. Teng, F.; Wei, L.; Yu, D.; Deng, L.; Zheng, Y.; Lin, H.; Liu, Y. Vertical bone augmentation with simultaneous implantation using deproteinized bovine bone block functionalized with a slow delivery of BMP-2. Clin. Oral Implants Res. 2020, 31, 215-228. [CrossRef]

46. Stigter, M.; Bezemer, J.; de Groot, K.; Layrolle, P. Incorporation of different antibiotics into carbonated hydroxyapatite coatings on titanium implants, release and antibiotic efficacy. J. Control. Release 2004, 99, 127-137. [CrossRef] [PubMed]

47. Ooya, T.; Eguchi, M.; Ozaki, A.; Yui, N. Carboxyethylester-polyrotaxanes as a new calcium chelating polymer: Synthesis, calcium binding and mechanism of trypsin inhibition. Int. J. Pharm. 2002, 242, 47-54. [CrossRef]

48. Liu, T.; Wu, G.; Zheng, Y.; Wismeijer, D.; Everts, V.; Liu, Y. Cell-mediated BMP-2 release from a novel dual-drug delivery system promotes bone formation. Clin. Oral Implants Res. 2014, 25, 1412-1421. [CrossRef] [PubMed]

49. Wu, G.; Hunziker, E.B.; Zheng, Y.; Wismeijer, D.; Liu, Y. Functionalization of deproteinized bovine bone with a coating-incorporated depot of BMP-2 renders the material efficiently osteoinductive and suppresses foreign-body reactivity. Bone 2011, 49, 1323-1330. [CrossRef]

50. Wu, G.; Liu, Y.; Iizuka, T.; Hunziker, E.B. The effect of a slow mode of BMP-2 delivery on the inflammatory response provoked by bone-defect-filling polymeric scaffolds. Biomaterials 2010, 31, 7485-7493. [CrossRef]

51. Liu, Y.; Schouten, C.; Boerman, O.; Wu, G.; Jansen, J.A.; Hunziker, E.B. The kinetics and mechanism of bone morphogenetic protein 2 release from calcium phosphate-based implant-coatings. J. Biomed. Mater. Res. A 2018, 106, 2363-2371. [CrossRef]

52. De Witte, T.-M.; Fratila-Apachitei, L.E.; Zadpoor, A.A.; Peppas, N.A. Bone tissue engineering via growth factor delivery: From scaffolds to complex matrices. Regen. Biomater. 2018, 5, 197-211. [CrossRef]

53. Hunziker, E.B.; Enggist, L.; Kuffer, A.; Buser, D.; Liu, Y. Osseointegration: The slow delivery of BMP-2 enhances osteoinductivity. Bone 2012, 51, 98-106. [CrossRef] [PubMed]

54. Wang, D.; Tabassum, A.; Wu, G.; Deng, L.; Wismeijer, D.; Liu, Y. Bone regeneration in critical-sized bone defect enhanced by introducing osteoinductivity to biphasic calcium phosphate granules. Clin. Oral Implants Res. 2017, 28, 251-260. [CrossRef] [PubMed]

55. Zhang, X.; Lin, X.; Liu, T.; Deng, L.; Huang, Y.; Liu, Y. Osteogenic enhancement between icariin and bone morphogenetic protein 2: A potential osteogenic compound for bone tissue engineering. Front. Pharmacol. 2019, 10, 201. [CrossRef] [PubMed] 
56. Liu, T.; Zheng, Y.; Wu, G.; Wismeijer, D.; Pathak, J.L.; Liu, Y. BMP2-coprecipitated calcium phosphate granules enhance osteoinductivity of deproteinized bovine bone, and bone formation during critical-sized bone defect healing. Sci. Rep. 2017, 7, 41800. [CrossRef] [PubMed]

57. Wei, L.; Teng, F.; Deng, L.; Liu, G.; Luan, M.; Jiang, J.; Liu, Z.; Liu, Y. Periodontal regeneration using bone morphogenetic protein 2 incorporated biomimetic calcium phosphate in conjunction with barrier membrane: A pre-clinical study in dogs. J. Clin. Periodontol. 2019, 46, 1254-1263. [CrossRef]

58. Wei, L.; Yu, D.; Wang, M.; Deng, L.; Wu, G.; Liu, Y. Dose effects of slow-released bone morphogenetic protein-2 functionalized beta-tricalcium phosphate in repairing critical-sized bone defects. Tissue Eng. Part A 2020, 26, 120-129. [CrossRef]

59. Schliephake, H.; Scharnweber, D.; Dard, M.; Röbetaler, S.; Sewing, A.; Hüttmann, C. Biological performance of biomimetic calcium phosphate coating of titanium implants in the dog mandible. J. Biomed. Mater. Res. A 2003, 64, 225-234. [CrossRef]

60. Paul, J.C.; Lonner, B.S.; Vira, S.; Kaye, I.D.; Errico, T.J. Reoperation rates after long posterior spinal fusion: Use of recombinant bone morphogenetic protein in idiopathic and non-idiopathic scoliosis. Spine Deform. 2016, 4, 304-309. [CrossRef]

61. Begam, H.; Nandi, S.K.; Kundu, B.; Chanda, A. Strategies for delivering bone morphogenetic protein for bone healing. Mater. Sci. Eng. C 2017, 70, 856-869. [CrossRef]

62. Haubruck, P.; Tanner, M.C.; Vlachopoulos, W.; Hagelskamp, S.; Miska, M.; Ober, J.; Fischer, C.; Schmidmaier, G. Comparison of the clinical effectiveness of bone morphogenic protein (BMP) -2 and -7 in the adjunct treatment of lower limb nonunions. Orthop. Traumatol. Surg. Res. 2018, 104, 1241-1248. [CrossRef]

63. Liu, T.; Wu, G.; Wismeijer, D.; Gu, Z.; Liu, Y. Deproteinized bovine bone functionalized with the slow delivery of BMP-2 for the repair of critical-sized bone defects in sheep. Bone 2013, 56, 110-118. [CrossRef] [PubMed]

64. Jiang, S.; Liu, T.; Wu, G.; Li, W.; Feng, X.; Pathak, J.L.; Shi, J. BMP2-functionalized biomimetic calcium phosphate graft promotes alveolar defect healing during orthodontic tooth movement in beagle dogs. Front. Bioeng. Biotechnol. 2020, 8, 517. [CrossRef] [PubMed]

65. Perez, J.R.; Kouroupis, D.; Li, D.J.; Best, T.M.; Kaplan, L.; Correa, D. Tissue engineering and cell-based therapies for fractures and bone defects. Front. Bioeng. Biotechnol. 2018, 6, 105. [CrossRef] [PubMed]

66. Ferguson, J.; Diefenbeck, M.; McNally, M. Ceramic biocomposites as biodegradable antibiotic carriers in the treatment of bone infections. J. Bone Jt. Infect. 2017, 2, 38-51. [CrossRef]

67. Kulkarni Aranya, A.; Pushalkar, S.; Zhao, M.; LeGeros, R.Z.; Zhang, Y.; Saxena, D. Antibacterial and bioactive coatings on titanium implant surfaces. J. Biomed. Mater. Res. A 2017, 105, 2218-2227. [CrossRef]

68. Dreyer, C.H.; Kjaergaard, K.; Ding, M.; Qin, L. Vascular endothelial growth factor for in vivo bone formation: A systematic review. J. Orthop. Transl. 2020, 24, 46-57. [CrossRef]

69. Wernike, E.; Montjovent, M.O.; Liu, Y.; Wismeijer, D.; Hunziker, E.B.; Siebenrock, K.A.; Hofstetter, W.; Klenke, F.M. VEGF incorporated into calcium phosphate ceramics promotes vascularisation and bone formation in vivo. Eur. Cell Mater. 2010, 19, 30-40. [CrossRef]

70. Wu, L.; Gu, Y.; Liu, L.; Tang, J.; Mao, J.; Xi, K.; Jiang, Z.; Zhou, Y.; Xu, Y.; Deng, L.; et al. Hierarchical micro/nanofibrous membranes of sustained releasing VEGF for periosteal regeneration. Biomaterials 2020, 227, 119555. [CrossRef]

71. Wu, Y.; Cao, H.; Yang, Y.; Zhou, Y.; Gu, Y.; Zhao, X.; Zhang, Y.; Zhao, Z.; Zhang, L.; Yin, J. Effects of vascular endothelial cells on osteogenic differentiation of noncontact co-cultured periodontal ligament stem cells under hypoxia. J. Periodontal Res. 2013, 48, 52-65. [CrossRef]

72. Coory, J.A.; Tan, K.G.; Whitehouse, S.L.; Hatton, A.; Graves, S.E.; Crawford, R.W. The outcome of total knee arthroplasty with and without patellar resurfacing up to 17 years: A report from the australian orthopaedic association national joint replacement registry. J. Arthroplast. 2020, 35, 132-138. [CrossRef]

73. Eckhardt, S.; Brunetto, P.S.; Gagnon, J.; Priebe, M.; Giese, B.; Fromm, K.M. Nanobio silver: Its interactions with peptides and bacteria, and its uses in medicine. Chem. Rev. 2013, 113, 4708-4754. [CrossRef]

74. Kang, M.-K.; Lee, S.-B.; Moon, S.-K.; Kim, K.-M.; Kim, K.-N. The biomimetic apatite-cefalotin coatings on modified titanium. Dent. Mater. J. 2012, 31. [CrossRef] [PubMed]

75. Li, M.; Liu, Q.; Jia, Z.; Xu, X.; Shi, Y.; Cheng, Y.; Zheng, Y. Polydopamine-induced nanocomposite Ag/CaP coatings on the surface of titania nanotubes for antibacterial and osteointegration functions. J. Mater. Chem. $B$ 2015, 3, 8796-8805. [CrossRef] [PubMed] 
76. Drugs Home Page. Available online: https://www.drugs.com/dosage/metronidazole.html (accessed on 11 April 2019).

77. Wang, D.; Liu, Y.; Liu, Y.; Yan, L.; Zaat, S.A.J.; Wismeijer, D.; Pathak, J.L.; Wu, G. A dual functional bone-defect-filling material with sequential antibacterial and osteoinductive properties for infected bone defect repair. J. Biomed. Mater. Res. A 2019, 107, 2360-2370. [CrossRef]

78. Gürbüz, K.; Yerer, M.B.; Gürbüz, P.; Halıcı, M. Icariin promotes early and late stages of fracture healing in rats. Eklem Hastalik Cerrahisi 2019, 30, 282-288. [CrossRef] [PubMed]

79. Li, M.; Gu, Q.; Chen, M.; Zhang, C.; Chen, S.; Zhao, J. Controlled delivery of icariin on small intestine submucosa for bone tissue engineering. Mater. Sci. Eng. C 2017, 71, 260-267. [CrossRef] [PubMed]

80. Xie, X.; Pei, F.; Wang, H.; Tan, Z.; Yang, Z.; Kang, P. Icariin: A promising osteoinductive compound for repairing bone defect and osteonecrosis. J. Biomater. Appl. 2015, 30, 290-299. [CrossRef] [PubMed]

81. Zhao, J.; Ohba, S.; Komiyama, Y.; Shinkai, M.; Chung, U.I.; Nagamune, T. Icariin: A potential osteoinductive compound for bone tissue engineering. Tissue Eng. Part A 2010, 16, 233-243. [CrossRef]

82. Zhang, X.; Liu, T.; Huang, Y.; Zheng, Y.; Wismeijer, D.; Liu, Y. Osteogenic potential of icariin compared with recombinant human bone morphogenetic protein 2 in vitro: A preliminary study. J. Biomater. Tissue Eng. 2015, 5, 226-233. [CrossRef]

83. Lombardi, G.; Ziemann, E.; Banfi, G.; Corbetta, S. Physical activity-dependent regulation of parathyroid hormone and calcium-phosphorous metabolism. Int. J. Mol. Sci. 2020, 21, 5388. [CrossRef]

84. Arrighi, I.; Mark, S.; Alvisi, M.; von Rechenberg, B.; Hubbell, J.A.; Schense, J.C. Bone healing induced by local delivery of an engineered parathyroid hormone prodrug. Biomaterials 2009, 30, 1763-1771. [CrossRef] [PubMed]

85. Kim, J.-H.; Kim, A.R.; Choi, Y.H.; Kim, A.; Sohn, Y.; Woo, G.-H.; Cha, J.-H.; Bak, E.-J.; Yoo, Y.-J. Intermittent PTH administration improves alveolar bone formation in type 1 diabetic rats with periodontitis. J. Transl. Med. 2018, 16, 70. [CrossRef] [PubMed]

86. Wojda, S.J.; Donahue, S.W. Parathyroid hormone for bone regeneration. J. Orthop. Res. 2018, 36, $2586-2594$. [CrossRef]

87. Yu, X.; Wei, M. Preparation and evaluation of parathyroid hormone incorporated CaP coating via a biomimetic method. J. Biomed. Mater. Res. B Appl. Biomater. 2011, 97, 345-354. [CrossRef] [PubMed]

88. Sun, P.; Wang, M.; Yin, G.-Y. Endogenous parathyroid hormone (PTH) signals through osteoblasts via RANKL during fracture healing to affect osteoclasts. Biochem. Biophys. Res. Commun. 2020, 525, 850-856. [CrossRef]

89. Kostenuik, P.; Mirza, F.M. Fracture healing physiology and the quest for therapies for delayed healing and nonunion. J. Orthop. Res. 2017, 35, 213-223. [CrossRef] [PubMed]

90. Spiller, K.L.; Koh, T.J. Macrophage-based therapeutic strategies in regenerative medicine. Adv. Drug Deliv. Rev. 2017, 122, 74-83. [CrossRef]

91. Lurier, E.B.; Dalton, D.; Dampier, W.; Raman, P.; Nassiri, S.; Ferraro, N.M.; Rajagopalan, R.; Sarmady, M.; Spiller, K.L. Transcriptome analysis of IL-10-stimulated (M2c) macrophages by next-generation sequencing. Immunobiology 2017, 222, 847-856. [CrossRef]

92. Chen, Z.; Klein, T.; Murray, R.Z.; Crawford, R.; Chang, J.; Wu, C.; Xiao, Y. Osteoimmunomodulation for the development of advanced bone biomaterials. Mater. Today 2016, 19, 304-321. [CrossRef]

93. Nathan, K.; Lu, L.Y.; Lin, T.; Pajarinen, J.; Jämsen, E.; Huang, J.-F.; Romero-Lopez, M.; Maruyama, M.; Kohno, Y.; Yao, Z.; et al. Precise immunomodulation of the M1 to M2 macrophage transition enhances mesenchymal stem cell osteogenesis and differs by sex. Bone Jt. Res. 2019, 8, 481-488. [CrossRef]

94. Gronowicz, G.; Jacobs, E.; Peng, T.; Zhu, L.; Hurley, M.; Kuhn, L.T. Calvarial bone regeneration is enhanced by sequential delivery of FGF-2 and BMP-2 from layer-by-layer coatings with a biomimetic calcium phosphate barrier layer. Tissue Eng. Part A 2017, 23, 1490-1501. [CrossRef] [PubMed]

95. Klopfleisch, R.; Jung, F. The pathology of the foreign body reaction against biomaterials. J. Biomed. Mater. Res. A 2017, 105, 927-940. [CrossRef] [PubMed]

96. Velard, F.; Braux, J.; Amedee, J.; Laquerriere, P. Inflammatory cell response to calcium phosphate biomaterial particles: An overview. Acta Biomater. 2013, 9, 4956-4963. [CrossRef] [PubMed] 
97. Knippenberg, M.; Helder, M.N.; Zandieh Doulabi, B.; Wuisman, P.I.J.M.; Klein-Nulend, J. Osteogenesis versus chondrogenesis by BMP-2 and BMP-7 in adipose stem cells. Biochem. Biophys. Res. Commun. 2006, 342, 902-908. [CrossRef]

98. Tsai, A.T.; Rice, J.; Scatena, M.; Liaw, L.; Ratner, B.D.; Giachelli, C.M. The role of osteopontin in foreign body giant cell formation. Biomaterials 2005, 26, 5835-5843. [CrossRef] [PubMed]

Publisher's Note: MDPI stays neutral with regard to jurisdictional claims in published maps and institutional affiliations.

(C) 2020 by the authors. Licensee MDPI, Basel, Switzerland. This article is an open access article distributed under the terms and conditions of the Creative Commons Attribution (CC BY) license (http://creativecommons.org/licenses/by/4.0/). 